ognized globally as centers of educational excellence. The first four positions are being located in Beijing (from February 2004), Washington DC (from mid-2005), Brussels (late 2005), and Kuala Lumpur (early 2006). Details on the location of the other three positions are yet to be released. The intention is that these counselors will be able to identify and share best practice in the field of international education between New Zealand and education providers in each of their respective locations.

The International Doctoral Scholarship Program, funded by the government, is designed to provide financial support to doctoral students undertaking research. In 2005, the year of its introduction, 40 such scholarships were awarded to students from designated countries in North America, Latin America, Europe, Asia, and the Middle East. Over the next two years, the program will be progressively expanded, with the aim that by 2007 up to Ioo doctoral scholarships will be awarded annually to applicants irrespective of country of origin. The objective behind this program is to share New Zealand's excellence with the rest of the world and to bring the best students from other countries to share their knowledge with New Zealand. Complementing this program, the government has also decided that from January 2006, all international students applying for doctoral studies at a New Zealand university will not be subject to international differential fees. This means that even if an international student does not gain a scholarship, they will be able to study for a New Zealand PhD at subsidized domestic fees. Similarly, from January 2006, school-aged dependents of international $\mathrm{PhD}$ students studying at New Zealand universities will not have to pay international tuition fees to attend New Zealand schools.

Through "education diplomacy," the govern-
ment is setting up seven offshore education
counselor positions to develop stronger and
deeper linkages. ...

The third initiative, the Innovation Fund, will support New Zealand education providers to develop new markets, new business models and structures, new delivery options for international education including offshore campuses, online programs and twinning arrangements with offshore education providers as well as the development of new educational programs. It is recognized by the government that insufficient innovation can be a detriment to the competitiveness and sustainability of the New Zealand's export education industry. Hence, the overall objective of this fund is to assist with the development of value-added activities. During the first four years, the fund will primarily target encouraging offshore initiatives. Compared to other competing countries, New Zealand currently relies almost exclusively on onshore delivery of international education. In encouraging offshore initiatives, the government is looking at diversifying risks. Similarly, the development of offshore education should benefit the sustain- ability of onshore education by acting as a marketing presence and providing potential pathways for international students to come study in New Zealand.

These three initiatives are aimed at keeping New Zealand's international education sector competitive in an increasingly dynamic industry. However, it is to be acknowledged that these policies are not a means to an end. The New Zealand government recognizes this reality and understands that its investment needs a long-term focus. Hence, we can expect to see more investment in the future.

\section{National Regulatory Approaches to Transnational Higher} Education

\section{LINE VeRBIK AND LISA JOKIVIRTA}

Line Verbik is a research officer and Lisa Jokivirta is deputy director at the Observatory on Borderless Higher Education, 36 Gordon Sq., London, WC1H OPF, United Kingdom. E-mail: I.verbik@obhe.ac.uk and l.jokivirta@obhe.ac.uk. URL: www.obhe.ac.uk.

Transnational higher education is not a new phenomenon, 1 but the pace of its global expansion is a new development. (Transnational is used here to designate higher education provided by one country in another and excludes provision where just the students travel abroad.) As foreign delivery becomes increasingly widespread, countries are facing a growing need to regulate this type of provision. Although many countries have yet to establish a clear regulatory framework for the import and export of transnational higher education, ambitions to regulate and offer quality assurance for this type of provision are an emerging international trend.

Transnational higher education serves different purposes in different countries. Overall, the perceived benefits of transnational delivery include domestic capacity building, broader student choice in education systems facing resource constraints, minimizing the resources flowing out of the country, reducing brain drain, and enhancing innovation and competitiveness in the sector. However, provision has a tendency to be concentrated in certain subject areas (e.g., business and information technology). While such provision undoubtedly meets a need, it is unclear to what extent it seriously addresses the development agenda of the host country and thus contributes to real capacity building. Experience with foreign education of low quality has made some countries wary of this type of provision and has prompted them to work on making the sector less of an open and easy market for foreign institutions. Concerns have frequently been raised over the quality of transnational provision, the impact on national authority over higher education, and unfair competition with domestic institutions.

Through a substantial research project, the Observatory has 
made an attempt to categorize regulatory frameworks for imported transnational provision into six main models. When a significant discrepancy exists between regulations and recognition (e.g., there are no legal barriers but recognition of foreign qualifications is virtually impossible), this is indicated (see "very restrictive" model). Many countries allowing transnational provision have a separate framework to address the recognition of foreign/transnational qualifications.

This article is not intended to provide an exhaustive examination of national regulatory approaches but rather an overview of different models and emerging trends. Some countries will not fit perfectly into a category. Not only is very little statistical data available about transnational provision (few countries systematically collect information on this type of activity), but it is also one of the most rapidly changing fields of higher education. The discrepancies that often occur between the letter and practice of the law are worth noting. The authority over regulation can also be unclear, given that many countries have a decentralized system where individual states or regions control the higher education sector.

\section{Transnational higher education serves differ- ent purposes in different countries.}

\section{Regulatory Models}

No regulations. There are no special regulations or control of foreign providers, which are free to operate without seeking permission from the host country. Examples include: Czech Republic, France, Malta, Mexico, Nigeria, Russia, Serbia, and Sri Lanka.

Liberal. Foreign providers must satisfy certain minimum conditions prior to commencing operations (e.g., official recognition in the home country). Examples include: Argentina, Bahrain, Estonia, the Netherlands, New Zealand, Norway, Peru, Slovenia, Sweden, Switzerland, and the United Kingdom.

Moderately liberal. The importing country is actively involved in licensing and (in some cases) accrediting transnational providers. This model requires that foreign institutions gain accreditation or other formal permission by the host country (e.g., Ministry of Education) prior to commencing operations. This category is diverse, ranging from compulsory registration to formal assessment of academic criteria. Requirements are generally straightforward and nonburdensome. Examples include: Australia, Bangladesh, China, Egypt, Hong Kong, Israel, Jamaica, Pakistan, Singapore, and Vietnam.

Transitional-from liberal to more restrictive. A more restrictive regulatory framework is gradually being introduced. Changes in legislation can include: compulsory registration and/or accreditation through the national system in order for foreign institutions to be allowed to operate and/or for their degrees to be recognized, requirements to establish a presence in the country, and criteria for collaboration between domestic and foreign institutions, as well as other factors. Example: India.

Transitional-from restrictive to more liberal. New legislation aimed at removing restrictions for foreign institutions wishing to operate in the country is being introduced. The new guidelines usually follow a period where regulations have practically ruled out transnational provision. In some cases, restrictions are only lifted in specified areas (e.g., South Korea), in others changes apply to the entire country (e.g., Japan). Examples include: Japan and South Korea.

Very restrictive-regulations concerning permission to operate. The government or another authoritative higher education body imposes strict requirements on foreign providers. Such institutions may be required to establish a physical presence in the country (i.e., franchised provision is not allowed), only institutions or programs accredited by the host country's agency are authorized, and foreign providers must change their curricula to be in line with domestic provision, and other factors. Examples include Bulgaria, Cyprus, South Africa, and the United Arab Emirates.

Virtually impossible recognition for qualifications obtained through transnational provision. The government does not recognize foreign qualifications obtained through transnational provision. Foreign institutions wishing to grant recognized degrees must become part of the national system (this option may not be straightforward). Examples include: Belgium (francophone) and Greece.

Emerging capacity-building model? If not legally mandated by the importing country, it is suggested that foreign institutions could increasingly be expected to adopt a development-based rhetoric to secure external support and funding from both the importing and exporting countries. Institutions are increasingly aware that to boost capacity, safeguard institutional reputation, and assist in the strengthening of domestic systems, a long-term commitment to the country through sustainable partnerships or other investment is required.

\section{The Main Findings and Observations}

The general trend appears to be allowing the import of transnational provision but increasingly attempting to regulate this type of activity. A trend toward adopting any one particular model, however, has not been detected.

There are signs that the issue of providing locally sensitive but sustainable transnational education will be of growing importance for exporting and importing institutions and countries.

A potential trend exists toward developing regulatory frameworks at the regional and international levels, although the actual impact remains less clear.

The Observatory would be grateful for information on countries not listed here (particularly those outside the English-speaking world), as well as any feedback on the examples provided. For further 
details, please refer to the two-part report "National Regulatory Frameworks for Transnational Higher Education: Models and Trends" at www.obhe.ac.uk.

\section{Innovations in the Allocation of Public Funds}

\begin{abstract}
Jamil Salmi and Arthur Hauptman
Jamil Salmi is coordinator of the World Bank's Tertiary Education Thematic Group. Arthur Hauptman is an independent public policy consultant specializing in higher education finance issues. Address: The World Bank, 1818 H St. NW, Washington, DC 20433, USA. E-mail: Salmi: jsalmi@worldbank.org; Hauptman: hauptman_a@yahoo.com. This article is drawn from a forthcoming World Bank paper on allocation mechanisms.
\end{abstract}

$\mathrm{T}^{\mathrm{n}}$ recent decades, a growing number of countries have 1 sought innovative solutions to the substantial challenges they face in financing tertiary education. One of the principal challenges, the demand for education beyond the secondary level, is growing in most countries around the world far faster than the ability or willingness of governments to provide adequate public resources.

The reasons for this rapid increase in demand are numerous. First, in virtually all countries, the economic value of attaining a tertiary education, as measured by rates of return or other factors, is growing faster than the economic returns accruing to those who receive a secondary education or less. Second, in many cultures strong social pressures are exerted on students for moving beyond the secondary level of education based on nonmonetary factors such as greater social standing and prestige in the community-sometimes even better marriage prospects for girls. Third, many countries are attempting to increase the relevance of tertiary education curricula as governments and tertiary education institutions deemphasize certain fields with low levels of labor force demand, such as public administration and education, in favor of fields more closely linked to emerging labor force needs, such as information technology, engineering, and science.

The demands placed on public resources are typically intense as governments around the world face challenges across the board in providing better health care, housing, transportation, agriculture, as well as the full range of education. In this context, tertiary education is often far from the highest priority for public funding in both industrial and developing countries.

Countries and institutions around the world have responded to this mismatch between available public resources and the growing demand for tertiary education in several generic ways. The most frequent response has been to mobilize more resources, principally by introducing or raising tuition fees as a means of increasing cost sharing. Another related response has been to seek increased private resources through the commercialization of research and other private uses of institutional facilities and staff. A third, perhaps less commonly found response, has been an increased reliance on bonds and other forms of creative financing that allow for greater public or private partnerships to provide services related to tertiary education activities.

A related trend has been the development of a variety of innovative allocation mechanisms that allow both public and private funds to go farther in meeting the challenges that tertiary education systems face around the world. Our recent study found these innovative mechanisms cover a broad range of approaches:

1. Funding methodologies for recurrent expenses and capital investment have evolved in a number of countries from the more traditional negotiations of budgets between governments and institutions to increasingly sophisticated funding formulas that aim to insulate allocation decisions from excessive political pressures and encourage desired institutional behavior.

2. As has recently happened in Colorado, some "demandside" voucher systems have been created in which institutional operating subsidies will be distributed through a voucher given to all undergraduates. In some cases, the allocation of fixed funds to institutions is based on the characteristics of enrolled students, an approach that might be referred to as "supply-side" vouchers.

\section{The growing diversity of funding sources has been an important response by governments and institutions to the mismatch between demand and resources.}

3. Performance-based funding mechanisms have been adopted in a number of countries. A portion of funding may be set aside to be distributed to institutions on the basis of a series of performance measures. Performance contracts are negotiated between governments and institutions. Competitive funding is introduced that encourages innovation, greater academic quality, and strengthening institutional management capacity. Another approach includes financing mechanisms that directly pay for results, either as part of the basic funding formula or as a separate set of payments of institutions.

4. In some countries financial aid has been substantially expanded for students with high levels of financial need or academic merit to allow for financing strategies that use higher fees to increase overall institutional resource levels, including student aid in the form of vouchers to stimulate competition among institutions-as an alternative to publicly funded but institutionally administered student aid programs.

5. In a number of countries tax benefits have been created to help students and their families offset the expense of tuition fees, as well as family allowances primarily designed to cover 